to the French tests. In round terms this would be 3 millirads, or $3 \%$ of one year's unavoidable exposure to natural background.

For the purposes of radiation protection it is assumed, but not proved, that any dose of radiation, however small, has some finite probability of doing harm. We cannot even say how much injury natural background radiation causes, and some might claim it causes none. The only way to reach some estimate of casualties is to pick a numerical coefficient for the risk of cancer (or other effect) per unit radiation dose, and calculate from that. The evidence from Japanese bomb survivors, who received 50-500 rads, and from antenatal diagnostic exposures at a mean dose of 2-5 rads, may suggest a cancer risk of 1 in 10,000 during a lifetime from a dose of $1 \mathrm{rad}$ continuing, as it would with fall-out, over a lifetime. We may assume, but certainly cannot prove, that the risk is exactly 1,000 times less for a dose of 1 millirad. If we do assume this, a world population of 4,000 million people each exposed to 3 millirads would experience 1,200 additional radiation-induced cancers. But this excess could never be demonstrated in the face of the 3 million cases which the same calculation would show to be the result of a lieftime's exposure to natural background radiation, or of the 1,000 million cancers occurring "spontaneously." Moreover, if the assumption that cancer risk is simply proportional to dose is not true, the numbers of radiation-induced cancers could be overestimated by a 100 -fold or 10,000 -fold or more.

Tropospheric fall-out of shortlived radionuclides in Australia after the French tests at Mururoa in 1970, 1971, and 1972 gave external doses of about 1,1 , and less than 0.1 millirad respectively. ${ }^{5-7}$ A similar risk calculation based on simple proportionality for the Australian population of 1213 million would suggest that this fall-out from the three successive series of tests would cause 1,1 , and zero cases of cancer respectively. The stratospheric fall-out from the same series of tests would be likely to cause a similar number of cancer cases in Australians.

All attempts to calculate risk or numbers of casualties from small doses of radiation, such as fall-out, or from the individually larger doses received in occupational exposure or radiological diagnosis, suffer from the same lack of a firm scientific foundation for ideas about the relationship between dose and risk and the same inability to make an observational check on the accuracy of conclusions. These uncertainties make it fruitless to argue too heatedly about the significance of quite sizeable differences in fall-out dose. Indeed quantitative assessments of numbers of casualties expected from radioactive fall-out, taken in isolation, seem to provide an inadequate argument against bomb tests. The important arguments relate to the benefits which justify radiation exposures, including medical ${ }^{8}$ and industrial. All radiation exposures should be justified by the expected benefit. ${ }^{9}$

1 United Nations Scientific Committee on the Effects of Atomic Radiation, Ionizing Radiation: Levels and Effects. United Nations, New York, 1972.
National Academy of Sciences-National Research Council, The Effects on Populations of Exposure to Low Levels of Ionizing Radiation. Washington D.C., 1972.

3 Peirson, D. H., Nature, 1971, 234, 79.

4 Peirson, D. H., unpublished information.

Australia Atomic Weapons Tests Safety Committee, Report AWTSC No. 1, Australia Government Publishing Service, 1971.

- Australia Atomic Weapons Tests Safety Committee, Report AWTSC No. 3. Australia Government Publishing Service, 1971.

7 Australia Atomic Weapons Tests Safety Committee, Report AWTSC No. 5, Australia Government Publishing Service, 1972.

8 Ministry of Health Committee on the Radiological Hazards to Patients, Second Report, London, H.M.S.O., 1960.

- International Commission on Radiological Protection, Publ. 9, Recommendations. Oxford, Pergamon Press, 1966.

\section{Screening for Glaucoma}

Between 1964 and 1966 screening for glaucoma was undertaken in Bedford, when 5,941 people over the age of 40 were examined.' People with a tension of $21 \mathrm{~mm} \mathrm{Hg}$ or greater and those with ophthalmoscopically abnormal optic discs were referred for more detailed study. Fifty-five cases of primary glaucoma were detected, a total incidence of $0.93 \%$, of which $0.71 \%$ represented the incidence of chronic simple glaucoma and low-tension glaucoma combined. A further 212 persons with equivocal or suspicious signs were advised to have an annual re-examination.

E. S. Perkins ${ }^{2}$ has recently reported on this last group, followed up over a period of five to seven years. A quarter failed to attend regularly and half have been discharged as showing on further study no evidence of glaucoma. Five cases of primary glaucoma (2.63\%) were discovered, and there remain 30 persons who are still under surveillance, two of whom may prove to suffer from chronic simple glaucoma.

The question posed on designing this survey was to what extent ocular hypertension as an isolated finding is a precurser of chronic simple glaucoma in view of the fact that $5 \%$ of the population have tensions of $21 \mathrm{~mm} \mathrm{Hg}$ or more. Of the 124 people with ocular hypertension followed up over seven years only four have developed chronic simple glaucoma, an incidence of $3 \%$.

The results of this follow-up study suggest that the risk of field defects developing in persons with moderate ocular hypertension over a seven year period is small, and treatment may legitimately be withheld until glaucomatous field changes declare themselves. But two further points should be kept in mind. If ocular hypertension is associated with suspicious signs at the optic disc, there is more likelihood of the development of glaucoma. Furthermore, the higher the tension on screening, the greater the probability of its development. ${ }^{3}$

Perkins $^{4}$ has also reported on a sample follow-up study, planned with a bias towards the older age group, of those persons who were dismissed as normal during the period 1964 to 1966; 770 individuals were re-examined. The most striking finding was the constancy of the tonometric readings after an interval of seven years in the great majority. Twelve of this group were found on their second examination to have tensions of $21 \mathrm{~mm} \mathrm{Hg}$ or above, two of whom were thought to be cases of chronic simple glaucoma. The Globuck screener disclosed 23 cases with field defects from various causes, two of which proved to be glaucomatous. There was a fifth case of probable chronic simple glaucoma in the 770 rescreened, making a total incidence of $0.52 \%$.

From these findings it is reasonable to question the widely held belief that raised tension precedes glaucomatous field defects probably by a decade. 5 They can certainly develop in a much shorter time, and evidence is accumulating to suggest that they arise suddenly and increase by steps. 6 The practical conclusion is that little weight should be given to a negative screening test carried out by present techniques. Nevertheless a change in tension to a higher level over a period of years, just as a change in extent of cupping of the optic disc with time, ${ }^{7}$ must always be considered to be a likely indication of the early development of chronic simple glaucoma.

Another point emerges from this study. Two out of 15 persons found to have suspicious discs and normal tensions 
on their first screening later developed chronic simple glaucoma. This is further evidence against the view that lowered outflow, raised tension, disc cupping, and finally field loss is the sequence of events in the development of this disease. It would seem that the majority of patients with glaucoma develop raised tension followed by cupping; some develop cupping before raised tension; and another minority develop both at the same time. It is difficult to avoid the conclusion that a common factor underlies both cupping and ocular hypertension, probably operating at different loci but not necessarily simultaneously or in a set order. 8

\footnotetext{
1 Bankes, J. L. K., Perkins, E. S., Tsolakis, S., and Wright, J. E., British Medical Fournal. 1968, 1, 791.

2 Perkins, E. S., British fournal of Ophthalmology, 1973, 57, 179.

Perkins, E. S., British fournal of Ophthalmology, 1973, $57,179$.

Perkins, E. S., Atti Societa Ottalmologica Italiana, 1967, 24, 181

Gerkins, E. S., British fournal of Ophthalmology, 1973, 57, 186.213.

Drance, S. M., British fournal of Ophthalmology, 1972, 56, 186.

' Miller, S. J. H., British fournal of Ophthalmology, 1972a, 56, 284. Miller, S. J. H., Transactions
}

\section{Detection of Biliary Tract Disease at Operation}

Various methods are available for detecting disease of the common bile duct at operation. Many surgeons probably rely on the findings at operation together with the patient's history. But the evidence shows that these methods are not in themselves enough. Stones may be missed, and unnecessary choledochotomies may be performed.1-3 Operative cholangiography is now widely carried out, for as well as adding to the accuracy of diagnosis it provides a permanent record which may be of help in the future management of the patient. The image intensifier will probably further improve operative cholangiograms. Preoperative intravenous cholangiography is not a reliable substitute for operative cholangiography.

Fibreoptic choledochoscopes have been available for some years. Though they have found favour on the Continent of Europe, they have not been so popular for routine use in Great Britain. Another procedure that has been undertaken in Europe is manometry of the bile ducts, but this too is little used in Britain. Recently a detailed study of the results obtained with it on 218 patients has been reported from Wales. ${ }^{4}$ The procedure is said to be safe, simple, and less time-consuming than operative cholangiography and to give results that justify more widespread use.

Manometry of the bile ducts is used to determine, firstly, the opening pressure of the sphincter of Oddi, that is, the pressure of saline necessary to produce a continuous steady flow of saline into the common duct; and, secondly, the volume of saline that can be introduced into the duct per minute at various heads of pressure. When these data are compared with those obtained in a model duct system the diameter of the ampulla of Vater can be calculated.

Gallstones anywhere in the duct system are believed to be associated with a raised opening pressure. An opening pressure of less than $16 \mathrm{~cm}$ of water is regarded as normal. An opening pressure of more than $30 \mathrm{~cm}$ of water is evidence of stones in the common duct or an obstruction at the lower end. Though ducts with an opening pressure of less than 16 $\mathrm{cm}$ of saline are stated to be normal, it is not clear precisely what criteria are used to confirm this. For example, did all of these patients have a normal cholangiogram to support this? About 30 patients in this series had pressures ranging from 16 to $30 \mathrm{~cm}$ of saline. In these cases the opening pressures are equivocal, and presumably cholangiography is needed in such circumstances to exclude duct lesions. As to diagnosis of stenosis of the ampulla of Vater, some critics might need more convincing. The size of the ampulla deduced from the flow data was confirmed by the passage of Bakes dilators, but the accuracy in this assessment of ampullary size may be questioned. Do different surgeons produce the same answer in a particular patient, or is there a significant observer error? Exponents of manometry advocate its use in assessment of the common duct after choledochotomy. But in $12 \%$ of patients examined in this way a persistently high opening pressure was recorded for which no pathological cause could be found. Nor is it clear whether bile duct manometry really is quicker than operative cholangiography.

In summary, it may well be that bile duct manometry is worthwhile, but further evidence would be welcome. Surgeons have been slow to adopt routine operative cholangioraphy despite the overwhelming evidence in its favour. They will require a clear demonstration that bile duct manometry adds to or improves on the information derived from a properly performed operative cholangiogram before abandoning it. A prospective controlled trial would settle this matter.

\footnotetext{
1 Havard, C., Annals of the Royal College of Surgeons of England, 1960, 26,

2 Le Quesne, L. A., Proceedings of the Royal Society of Medicine, 1960, 53,

852.
3 Kako, G. S., Tompkins, R. K., Turnipseed, W., and Zollinger, R., Archives of Surgery, 1972, 104, 484.

Daniel, O., Annals of the Royal College of Surgeons of England, 1972, 51, 357.
}

\section{Medicine in Old Age}

Geriatricians sometimes complain about the phrase, "We're all geriatricians nowadays," used by their colleagues in general medicine and surgery. Yet this flippant remark refers only to the average age of patients in most general wards and certainly does not challenge the legitimacy of geriatrics as a specialty in its own right. Indeed, the rapid development of geriatrics has been a particularly British feature, and factors such as full-time consultants, day hospitals, and university departments in the specialty have done much to convert mere existence into a full life for many patients in this age group. The forthcoming reorganization of the Health Service may spread full community care for the old more evenly over the whole country, and hence it is appropriate to consider recent developments in geriatrics. This week we begin a new series 'of "Medical Practice" articles on "Medicine in Old Age," designed to cover important aspects of geriatric care for the non-specialist reader. We hope that these will be found a useful introduction to an important subject.

\section{Industrial Action and the B.M.J.}

The B.M.f. is among those publications affected by continuing industrial action. We regret the inconvenience caused to our readers. 